\title{
ROBERTO BOLAÑO: BAILES Y DISFRACES
}

\author{
Sergio Marras
}

Inspirado en la pintura de Giuseppe Arcimboldo —advierte Sergio Marras en estas páginas- Roberto Bolaño inaugura una narrativa cuyo rasgo diferenciador es la concepción de la obra como un conjunto de partes independientes que concurren a engendrar una naturaleza mayor con elementos siempre provisorios y nómades.

Bolaño crea un personaje central, Arturo Belano, también llamado B, que asume la literatura como un sistema político, reglado por el Mercado Editorial y la Crítica, en el que intenta sobrevivir y triunfar aunque no se siente cómodo en él. Para eludirlo, Belano crea su personaje esencial, Benno von Archimboldi, un antihéroe que ignora cualquier poder que pretenda establecer un canon. B resucitará en Archimboldi y conseguirá ser el escritor que no pudo ser en vida reinventando su constitución literaria.

Palabras clave: Roberto Bolaño; literatura hispanoamericana; Giuseppe Arcimboldo.

Sergio Marras (1950, Santiago de Chile) es Doctor en Literatura Hispanoamericana de la Universidad de Chile, y periodista y sociólogo de la Pontificia Universidad Católica de Chile. Autor de las novelas Las Ganas Locas (Planeta, 1990); Carta Apócrifa de Pinochet a un Siquiatra Chileno (Demens-Sapiens, 1998); y Por Qué Lloran los Hombres (Cuarto Propio, 2003), y de las obras de teatro Macias, Ensayo General sobre el Poder y la Gloria (1984) y La Edad Media, Premio Consejo Nacional del Libro 1996 del Ministerio de Educación de Chile. Entre sus libros periodísticos, a su vez, se encuentra el conjunto de entrevistas América Latina, Marca Registrada (Ediciones B, 1992). Reside en Madrid.

Estudios Públicos, 119 (invierno 2010). 


\section{El enigma arcimboldiano}

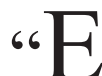
(1523-1593) llena una sala del castillo de Skokloster, cerca de Estocolmo. Al verla, una mano implacable empuja, sin dar respiro, hacia la base misma del cuadro. Acercándose, aquella figura, que en la lejanía parecía un estudiante alerta esperando un examen, se transforma en una torre de libros de diversos tamaños, texturas y disposiciones, los mismos que poco antes se negaban a exhibirse individualmente. Imaginar el cosmos a partir de fragmentos autónomos, o, si se quiere, de universos más pequeños, es una manera de conjeturar el mundo que puede resultar iluminadora y tremendamente estimulante.

Desde que la vi, esta pintura se me convirtió en una obsesión. Perseguí la obra arcimboldiana por el Museo de Historia del Arte de Viena, por el Louvre de París. Conseguí buena parte de sus libros y muchas reproducciones de sus cuadros. "Los Cuatro Elementos", "Las Cuatro Estaciones", "El Asado", muestran materiales que gestan nuevos mundos capaces de suscitar, como en un big bang, cientos de significados que no sabemos si se cruzarán alguna vez formando universos mayores que podremos percibir o se diluirán en la nada. En la obra arcimboldiana las manifestaciones de la vida parecen a primera vista naturalezas parciales, traslapadas, enconadas e imbricadas que, sin saber cómo, se conjugan en entes totales que a su vez dan a la luz otros territorios y lejanas existencias en una vertiginosa puesta en abismo.

Mi sorpresa fue inmensa cuando, acicateado por un amigo que conocía mi afición por la obra de Arcimboldo, leí Los Detectives Salvajes, en 1999, del escritor chileno mexicano catalán, Roberto Bolaño, y advertí que su literatura está intrínsecamente relacionada con la cosmovisión arcimboldiana. Desde entonces su obra narrativa se me transformó también en obsesión. Al pasar sus páginas no me cupo duda de que Bolaño inauguró una narrativa hispanoamericana distinta, cuyo rasgo diferenciador es concebir la obra como algo más que la suma de cada libro, como un conjunto de partes identificables e independientes, cada cual con vida y trayectoria propias, que concurren a engendrar una esencia mayor: como un gran tubérculo con miles de raicillas que conforman realidades inasibles que van a dar a lugares que no conocemos y que a veces — pocas veces - satisfacen un itinerario reconocible que llamamos convencionalmente una historia. 


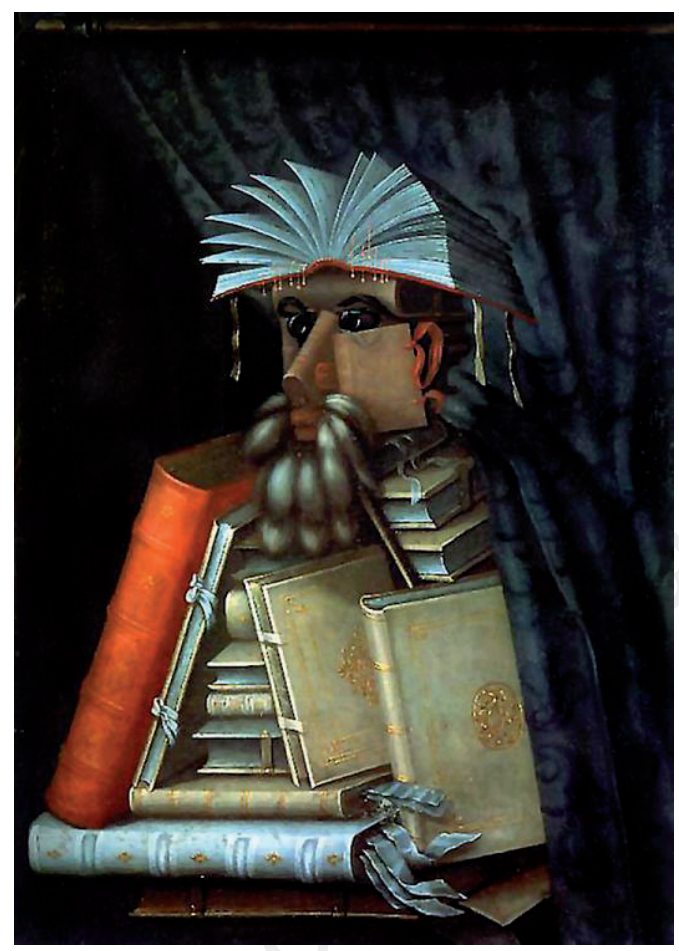

"El Bibliotecario", de Giuseppe Arcimboldo.

No me extrañó entonces que el pintor Arcimboldo, como tal, apareciera en los cuadernos de Boris Ansky, esos extraños papeles que inspiraron al joven Hans Reiter en la Ucrania de la Segunda Guerra Mundial y lo impulsaron a ser escritor y a convertirse en Benno von Archimboldi, personaje pilar de la novela 2666. En esos cuadernos, Ansky confiesa admirar la destreza de Giuseppe Arcimboldo para asociar diversas imágenes que revelan otra mayor.

Menciona el cuadro "El Asado", por ejemplo, y dice que al mirarlo de frente se puede ver un gran plato con un lechón y un conejo asados y unas manos tapando la carne para que no se enfríe. Al verlo al revés, sin embargo, se puede distinguir la cara de un soldado desdentado, con casco, armadura y una sonrisa maligna de mercenario. Según Ansky, Arcimboldo quiere decir que si bien el todo está en el todo, éste se encuentra fundamentalmente en la parte. Y la visión del todo y la parte es siempre provisoria; premisas que pasarán a ser un leit motiv en la vida de Reiter y serán fundamentales en la estructura del gran relato 


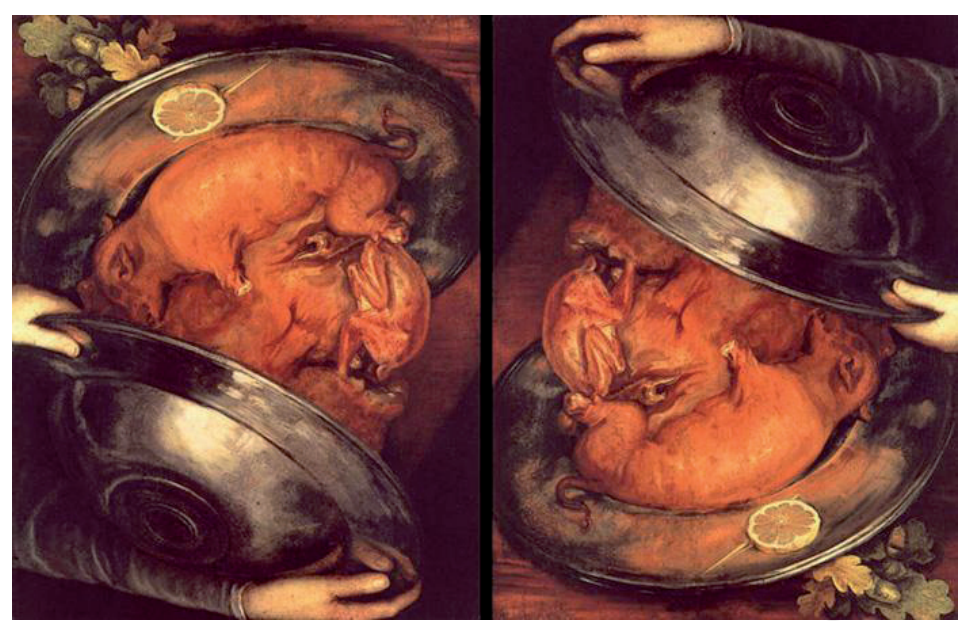

"El Asado", de Giuseppe Arcimboldo.

bolañesco. Ambas se transforman en características sine qua non de la Weltanschauung literaria de Bolaño, en la base de su sistema narrativo en el que cada obra es parte de un todo que puede verse, y leerse, desde distintos lugares con alcances diversos, y cuyo significado completo puede estar a la sombra de varios significados particulares. Totalidad que a su vez es provisoria, parte de otra aun mayor y en construcción, signo categórico de una concepción de la vida y la literatura en permanente multiplicación y aventura.

La pintura "El Bibliotecario" de Arcimboldo es, entonces, su gran metáfora, y tiene una clara raigambre borgeana y, cómo no, cervantina. El cuadro es un cosmos que además de narrar su propia historia, cuenta la de sus partes en un genial rompecabezas que sólo se puede adivinar a larga y corta distancia. Así la ficción de Bolaño se constituye como un sistema narrativo polifónico global que sumerge en un mismo universo cada una de sus obras, pero a la vez da a todas ellas una identidad propia. Sus novelas y cuentos establecen un espacio y un tiempo ligados que superan el de cada novela y cuento particular. Sus tramas se desarrollan dentro de una conjunción espacio temporal determinada tanto geográfica como cronológicamente, en función de un camino acotado que incluso a veces corre por fuera de cada texto.

Este sistema polifónico conforma un sistema infinitamente abierto de progresión explosiva. Los textos cruzan desde un lado a otro la 
inestable frontera entre realidad y ficción con voces que saltan de una obra a otra y hacen guiños a la realidad exterior y por supuesto al lector. Ocasionalmente se reproducen y crecen en el viaje entre historias, o se relacionan con otras tramas de distinto género - ensayístico, periodístico o poético- que también forman parte de su espacio tiempo narrativo. Se construye así una ficción-realidad única. Una polifonía que canta desde dentro y fuera de sus soportes ${ }^{1}$.

La participación del lector, por otra parte, es importantísima, ya que pasa a ser nada más y nada menos que el último eslabón de esa cadena polifónica, la gran oreja enciclopédica que cerrará la percepción y recreación del sistema narrativo bolañesco con mayor o menor sensibilidad.

¿Cómo se manifiesta todo lo dicho en la manera de mirar el mundo en las 10 novelas y 34 cuentos que escribió Bolaño y alcanzó a revisar?

Las historias confluyen en una gran acción en curso que es tanto o más importante que Arturo Belano, al que también llamaremos B; y Benno von Archimboldi, los personajes que sujetan la estructura de su gran trama. Esta amplia acción está destinada a la búsqueda del sentido de la vida en la literatura, y, por lo tanto, al sentido último de ésta a través de la supervivencia de unos personajes que se han dedicado por completo a ser escritores con el fin de resistir a la muerte y a diferentes poderes fácticos como la Crítica y el Mercado Editorial.

B convierte a la literatura en un sistema político en el que tiene que sobrevivir y triunfar. Von Archimboldi, el antihéroe de B creado por el mismo dentro de su trama, desprecia cualquier canon literario y poder que intente establecerlo, y se da el gusto de escribir por escribir.

Comencemos por el personaje B. Para entender la obra de Roberto Bolaño es imprescindible remontarse a su primer y máximo héroe: él

${ }^{1}$ Es tan cierto que sus tramas se salen de sus soportes que recomiendo leer distintas reseñas biográficas de Hans Reiter en internet que coinciden en señalar que fue un médico nazi que murió en Alemania. Sin embargo, en la modificable Wikipedia, se agrega que fingió su muerte, huyó a Bariloche donde falleció escribiendo con el seudónimo de J.M.G. Arcimboldi, lo que lo liga al Reiter de Bolaño. Según esta versión, vivió en Francia y se relacionó con los escritores pro nazis Robert Brasilach y Pierre Drieu La Rochelle y, por este motivo, habría escrito en francés. ¿Escribió Bolaño en Wikipedia o lo hizo alguno de sus seguidores? Sea cual fuere el caso, hay un vínculo real del grupo pro-nazi francés con Argentina. Drieu La Rochelle visitó Buenos Aires en 1933, fue amante de Victoria Ocampo y amigo de Jorge Luis Borges. No es inverosímil que, algunos años después, Reiter, hubiera sido escondido por algún amigo de Drieu La Rochelle. 
mismo, con la sucesión de nombres propios y alter egos que desarrollará en el tiempo.

Bolaño organiza y diseña al personaje B primero como un personaje autor/actor que está presente en poco más de la mitad de su obra; personaje que participa personal y directamente como narrador en primera persona, como protagonista narrado o receptor de la narración. Su principal manifestación está en Los Detectives Salvajes. Y luego, en una segunda faceta, organiza y diseña un autor/escritor que se permite escribir cuentos y novelas dentro de las peripecias del autor/actor, obras que aparentemente pueden alejarse de la temática de este último, pero que lo van reconstruyendo como sujeto para que sobreviva y llegue a destino. Su principal manifestación está en 2666. Como prueba Arturo Belano nos dejó por escrito, fuera de la obra, que no fue otro que él quien escribió 2666.

Ambas facetas son parte del gran relato a que hemos hecho referencia, que da cuenta de un calendario y una geografía, que se mueve apoyado en múltiples asociaciones y construye una metáfora única que da pie a que se provoquen relaciones directas con la realidad exterior.

Bolaño asume como protagonista desde su primera novela, $\mathrm{Am}$ beres, escrita en Barcelona en 1980 y publicada en esta ciudad el año 2002 por la editorial Anagrama ${ }^{2}$. En ella aparece como un narrador héroe que instala su nombre propio sin ninguna ambigüedad. Amberes da el puntapié inicial a toda su imaginería. A partir de ella, apurado por ir más allá de sus propias fronteras, se transformará en Arturo Belano, sólo en B, en un narrador sin nombre, o en el alter ego de dos caras Gaspar Heredia/Remo Morán, vértice del triángulo narrativo de la novela La Pista de Hielo, para poder así seguir existiendo sin los límites que le impone el nombre Roberto Bolaño.

B personaje, desde el mismo comienzo de la trama narrativa, armará su derrotero con una explosión anárquica. Es decir, no sólo encontraremos tramas continuadas con causa conocida, sino que también enfrentaremos digresiones que irán a parar a otras tramas que nunca se unirán con las primeras. Es el árbol plagado de ganchos y tubérculos,

2 Se discute si Amberes es una novela o un largo poema, ya que se mueve en los límites de ambos géneros. En uno de los libros póstumos de Roberto Bolaño, La Universidad Desconocida, publicado por Anagrama en 2007 (p. 177), se reeditan como poemas independientes cada uno de los 56 textos que componen Amberes. Se los agrupa bajo el subtítulo "Gente que se aleja". Yo sigo el criterio de Bolaño, que publicó esos textos como una novela. 
en pleno crecimiento y multiplicación en direcciones extremadamente variables, que mencioné antes.

Después de Amberes, el nombre propio Bolaño, como personaje, aparecerá por última vez en la novela La Literatura Nazi en América y en algunos cuentos, hasta que se produce el punto de quiebre que lo llevará a crear la cadena de alter egos mencionada, la que utilizará hasta el fin de su producción narrativa, desembocando en la creación de su propio antihéroe $-\mathrm{y}$ segundo personaje estructural de su trama- Benno von Archimboldi.

Podemos deslindar cuatro hitos fundamentales en la gestación fragmentada del personaje Bolaño, que luego se transformará en Belano, o B.

En primer lugar, la novela Amberes, como inicio de la escritura en prosa de Roberto Bolaño en solitario, donde encontramos los momentos de la aparición del personaje y donde están presentes varios rasgos centrales, escenarios, personajes y argumentos que se desarrollarán en su obra posterior.

Enseguida, el capítulo, si así puede llamársele, "Carlos Ramírez Hoffman, el infame", de La Literatura Nazi en América, y su secuela, la novela Estrella Distante, donde hallamos el gran punto de inflexión de la narrativa bolañana que da paso a Arturo Belano, su primer alter ego.

El tercer hito es la novela Los Detectives Salvajes, en la que es posible rescatar prácticamente toda la vida del personaje como un itinerario. Ella nos provee de un derrotero casi completo además de innumerables rasgos únicos de $\mathrm{B}$. Tanto los rasgos como el itinerario serán reforzados y validados con información proveniente de algunos cuentos incluidos en los libros Llamadas Telefónicas y Putas Asesinas, en los que B participa, narra o es narrado en su faceta de autor protagonista.

Una vez cumplidos estos tres momentos, en 2666 se producirá la vuelta de tuerca. Aparecerá el antihéroe Archimboldi que vendrá a refundar al personaje B. En el caso de la gestación de Archimboldi los hitos son básicamente dos: su aparición primera como el escritor J.M.G. Arcimboldi en Los Detectives Salvajes y después como Benno von Archimboldi en 2666.

\section{Amberes, el magma iniciático}

La novela Amberes inicia la escritura en prosa de Roberto Bolaño. Está narrada en cincuenta y seis fragmentos. En ellos se sucede 
una multiplicidad de historias protagonizadas por personajes diversos y aparentemente desconectados entre sí: una pelirroja que se desnuda, un espía jorobado que alterna con viejos policías; un escritor inglés que proyecta una película en medio de un bosque; un sudamericano indocumentado que agoniza en un dormitorio hediondo del camping que administra y en el cual ha ocurrido un homicidio; oscuros detectives que hacen el amor con muchachas sin nombre.

En esta novela el narrador personaje Roberto Bolaño va saltando de una historia a otra, abriendo y cerrando puertas, dejando finalmente algunas abiertas de par en par para que explote su universo como en un big bang, imagen que el escritor argentino Rodrigo Fresán patentó en un artículo en el periódico argentino Página 12, donde convertía a Amberes en un magma originario que Bolaño autor recoge y destila como material básico de su narrativa en progreso. A partir de este magma fragmentado se constituyen escenarios, estrategias y personajes inconfundibles que poblarán sus escritos posteriores y crecerán en ellos. Así comienzan a establecerse sus primeros trazos globales.

Tempranamente aparece en Amberes la literatura como el universo contenedor del itinerario bolañano, una especie de campo de fútbol infinito, "aquel vasto campo minado", según lo llama él mismo en uno de sus escritos. Un panóptico desde donde todo se escudriña y somete de acuerdo a sus propias reglas políticas. Dentro del cosmos y de la simbología de la literatura, bajo la supervigilancia de sus cánones, los personajes desatan sus motivos, contradicciones y pasiones. La literatura es usada por Bolaño como arma y medicina, pero también como patrón de vida. La desarrolla como un sistema de poderes en tensión. Para el narrador personaje, sus modos y medios son una estrategia de supervivencia en que el universo de lo escrito, con todo lo que involucra - escritor, personajes y lectores - , se despliega en un territorio donde ciertas relaciones de poder, deseo y resistencia imponen unas maneras propias de producir y de vivir.

Para sobrevivir en la literatura será capaz de derrotar, en parte, su trágico albur personal: la enfermedad, ese gran tema matricial suyo que también asoma en Amberes, donde el personaje narrador, al igual que el Roberto Bolaño real, es un enfermo condenado a muerte. A partir de esta situación límite establece escenarios que perdurarán durante toda la construcción de su obra. 
Entre los lugares establecidos en Amberes aparece en primer lugar el Camping, entidad que forma parte esencial de la escenografía de Bolaño. Es un territorio que reúne perseguidos, fugitivos de sí mismos, que se recluyen simplemente a esperar. Es un purgatorio, un lugar de sufrimiento pasajero para pagar cuentas pasadas o para ir al encuentro de tiempos mejores.

En Amberes, B emerge por primera vez como cuidador de un camping, ejerciendo de guardián del llamado La Calabria, con sus moradores perseguidos, discriminados, bajo sospecha, molestados por la gente del pueblo y por la Brigada Antiterrorista. El único desasosiego de su cuidador es el desmadre de sus moradores, que arman orgías en la playa y provocan escándalos ante la policía y el pueblo. El camping se transforma en un lugar de asilo de los detentadores del deseo contra la opresión de los conservadores del poder, un lugar que nadie se atreve a invadir o profanar. También aparece tempranamente en este texto el camping más famoso de sus historias, el Estrella de Mar.

En Amberes, del mismo modo, surgen anticipadamente otros lugares que después formarán parte de la escenografía de Bolaño: el Cine, ensalzado como un lugar de reflexión existencial, un espejo de la vida que a la vez influye en ella y donde se pueden encontrar historias dentro de la historia que siempre escapan fuera de la pantalla. Historias que son a la vez fundamentales para que los personajes recapaciten sobre la trama en que están involucrados, como en el caso de las pistas criminales que deja Ramírez Hoffman cuando se convierte en R.P. English, camarógrafo de películas porno, pistas que harán finalmente que Belano y el detective Abel Romero den con su paradero.

El cine arropa reflexiones de B y sus alter egos, que muchas veces son pequeños ensayos sobre el mundo o destellos de señales de resistencia o símbolos ocultos de su propia vida. Amberes, con sus efímeras proyecciones en el bosque, nos anuncia el cine tan importante de Monsieur Pain, donde el personaje Aloysius Pleumeur Bodou entrega claves sobre la definición de la historia y parte de su pasado a través de lo que sucede en la pantalla.

O en el cuento "El Gusano" de Llamadas Telefónicas, en el que B explica la importancia del cine en su educación carnal; la educación que le brinda el nuevo cine erótico mexicano, el cual, mezclado con el nuevo cine de terror nacional, termina siendo esencial para su concepción del sexo. 
Asimismo, la película sobre el fabricante de campanas, que aparece en el cuento "Días de 1978", que tiene que ver con su aprendizaje de resistencia. Cuenta la historia de un adolescente, hijo de un fundidor, que tras la muerte del padre convenció a su señor de que él sabía fabricar una campana. Los guardias le advirtieron que pagaría con su vida si el instrumento resultaba defectuoso. Cuando llegó el gran día, el repique fue perfecto. El adolescente confesó que su padre jamás le enseñó a fabricar campanas, que aprendió solo... La resistencia de B ante el padre aparece como el periscopio de un submarino desde las profundidades de su propia conciencia. A ella se puede sumar la sucesión de películas pornográficas en "Prefiguración de Lalo Cura", que fragmenta cualquier posibilidad de pertenencia a un sistema establecido y que se transforma en puro deseo de resistir. Atributo que B convierte posteriormente en su marca de fábrica.

También emerge en Amberes la Calle como escenario central a través de un símbolo que estará presente en buena parte de su obra: la calle Bucareli donde se encuentra el infaltable Café Quito, versión literaria del Café La Habana de Ciudad de México. Es el epítome de todas las calles de Bolaño, tanto del DF como de Roma o Barcelona. Desde Amberes, Bucareli aparece en todas las novelas donde B es protagonista. La Pista de Hielo comienza en ella. "Lo vi en la calle Bucareli..." Remo Morán nos introduce a la visión de la calle bolañesca, cargada de significados que van más allá de lo estrictamente urbanístico. Incorpora la carga interior y sentimental, definiéndola como una zona borrosa y vacilante de su adolescencia. La calle Bucareli atravesará buena parte de la obra de Bolaño como un hilo imprescindible.

El escenario siguiente es la Ciudad como campo de batalla, con características permanentes de zona de guerra. El DF de Los Detectives Salvajes; la Barcelona de los cuentos; el París de Monsieur Pain y "Henri Simon Leprince"; la Roma de Una Novelita Lumpen; o la Concepción de Estrella Distante. Todas ellas son campos de batalla donde la derrota conduce a la muerte o al desamparo.

En Amberes están presentes la mayoría de los territorios esenciales donde el personaje B desarrollará su obra posterior. A partir de Monsieur Pain y de Los Detectives Salvajes se sumarán, otros dos lugares ineludibles: el Hospital y el Desierto.

En Amberes surgen también ciertos personajes que circularán por los textos de $\mathrm{B}$, erráticos, sometidos a relaciones de poder que les 
imponen estructuras ocultas que les envían mensajes cifrados por medio de recaderos misteriosos e implacables con el fin de que se den por vencidos y queden paralizados.

Entre estos mensajeros predominan los policías y los detectives. Aparecen como interlocutores sospechosos, o facinerosos presuntos, que pretenden resolver crímenes que a veces han cometido ellos mismos. También circulan inmigrantes perseguidos por todos, pero sobre todo por sus propias conciencias. Juegan un papel en la guerra de la ciudad, rebelándose contra los dominadores, aunque siempre sucumben al final. Irrumpen asimismo los poetas malditos con sus libros tótems y su atractiva penumbra. Asoma el enfermo, que puede ser terminal o terminado, es decir, alguien con un defecto irrecuperable, un jorobado o un deprimido, o alguien que pronto morirá porque está desahuciado. Surge por otra parte la chica deseada, capaz de blandir un cuchillo y su filo restaurador como medio de validación social y sicológica. Esta chica puede brotar como una sofisticada prostituta, como una sacrificada enfermera de hospital, como una universitaria histérica o como una ex amante indolente y siempre dispuesta a que B se juegue por ella y la ampare. Puede encarnarse en amores primerizos, dolorosos, devotos, accidentales o pedagógicos, entre otros. O bien en cuidados de madres sublimes de las que B no sabe escapar. La pelirroja de Amberes es el origen de Clara, Sofía, Mary Watson, Anne Moore, Perla Avilés, Simone Darrieux o Laura Jáuregui y de todas las demás protagonistas mujeres de B. También de aquellas aparentemente asexuadas como Auxilio Lacouture y Cesárea Tinajero.

En Amberes, asimismo aflora la intimidación como punto de inflexión temático, adosado a una seña especial: el cuchillo, un arma preferida, que asoma siempre en los momentos más apremiantes en formas muy diversas: un tip top cartonero, una navaja, un cortaplumas, un punzón, un cuchillo carnicero o una daga árabe. Un arma que amenaza pero nunca corta, salvo en el excepcional crimen de La Pista de Hielo.

Amberes, si bien es la novela más breve de Roberto Bolaño, de tan solo ciento veinte páginas, contiene el embrión de casi todo lo posterior, lo cual nos permite sospechar que estamos a las puertas de un gran relato pleno de intertextualidades y diferentes tipos de conexiones. Es un universo en expansión. Es origen puro. No hay historia. Los personajes no se relacionan entre sí. Son los colores de la paleta arcimboldiana arrojados en desorden contra la tela. 
La mayor parte de sus fragmentos son un arranque movilizador que retumbará en las páginas de todos los escritos venideros de Bolaño.

\section{2. "Carlos Ramírez Hoffman, el infame" y Estrella Distante: La transgresión de la (auto) biografía}

\section{La Literatura Nazi en América}

Algunos años después de la escritura de Amberes, en 1996, Bolaño vuelve a aparecer como personaje, con nombre y apellido. Ocurre en el último episodio de La Literatura Nazi en América, el llamado "Carlos Ramírez Hoffmann, el infame", narrado en primera persona por el personaje Roberto Bolaño. La historia transcurre en Chile en la época que sigue al Golpe de Estado de 1973.

La Literatura Nazi en América es una especie de tratado o de manual apócrifo que pretende dar a conocer la biografía y los escritos de autores latinoamericanos, y de algunos norteamericanos, que de alguna manera manifiestan algún rasgo nazi, fascista o autoritario en su vida o en sus escritos. Podría ser confundida fácilmente con un verdadero compendio de escritores que existen o existieron; sus textos están apoyados por largas bibliografías respaldadas por falsas revistas especializadas. Las fuentes de La Literatura Nazi en América aparecen en un apéndice llamado "Epílogo para monstruos", lleno de precisos datos imaginarios.

Las descripciones y referencias de los treinta personajes principales logran dar una gran verosimilitud a los textos y los sumergen en un contexto histórico aparentemente verídico.

En "Ramírez Hoffman" relata en primera persona su experiencia en el Chile de los días inmediatamente posteriores al golpe militar de 1973, aunque también hace una breve referencia a los meses previos, cuando Ramírez Hoffman participaba en un taller literario con el nombre postizo de Emilio Stevens y pretendía con éxito a sus co-talleristas, las hermanas Venegas, para envidia de Roberto Bolaño personaje, quien narra este episodio desde una prisión: el Centro La Peña, cerca de Concepción. Más adelante hará la narración de su arresto, en los cuentos "Detectives" y "Carnet de Baile", y en la novela Los Detectives Salvajes. 
Ramírez Hoffman es un teniente de la Fuerza Aérea de Chile que escribe con humo versos en el cielo. Por la noche ejecuta las más grandes salvajadas criminales, no sólo con los opositores al régimen sino también con sus compañeras poetas, monstruosidades que culminan en una siniestra exposición fotográfica privada en la que aparecen mujeres destripadas y cortadas en pedazos; arranques artísticos que llegan a escandalizar a los propios militares.

A partir de esa exposición, Ramírez Hoffman huye y se transforma en un mito. Se lo ve en todas partes y en ninguna. En la práctica desaparece. Hasta que veinte años después Bolaño lo identifica en un pueblo de la Costa Brava, por petición del detective privado chileno Abel Romero.

En aquel episodio carcelario de La Literatura Nazi en América, el nombre propio Roberto Bolaño aparece por segunda y última vez, después de Amberes, cuando Norberto, su compañero de prisión, se dirige a él por su apellido.

"Era un Messerschmitt, Bolaño, te lo juro por lo más sagrado, -me dijo Norberto mientras entrábamos en el gimnasio."

Se vuelve a mencionar su nombre al final del capítulo, cuando Bolaño es visitado en Barcelona por Abel Romero, dos décadas después de los acontecimientos. Romero está buscando a Ramírez Hoffman en Europa. Encarga a Bolaño la tarea de investigar su presencia en revistas de literatura y videos pornográficos franceses y alemanes. Bolaño finalmente lo identifica - gracias a una sugerencia del detective, basada en pistas entregadas por la actriz porno Joanna Silvestri en el cuento homónimo - como camarógrafo de películas pornográficas snuff, aquellas en que se muestran crímenes reales especialmente perpetrados para las cámaras.

Romero propone a Bolaño identificarlo físicamente en un café de Lloret de Mar, un pueblo cercano a Barcelona y a Blanes, donde vive. Una vez que B lo reconoce, Abel Romero se encarga de él y menciona al personaje Bolaño por última vez por su nombre propio.

"Lo miré, allí, de pie en medio del portal. Romero sonreía. Debía andar por los sesenta años. Cuídate, Bolaño, dijo finalmente y se marchó."

Allí terminaría la historia, si a partir de ella no se avecinara un punto de inflexión en que Bolaño cambia la manera de abordar su narrativa, la que hasta aquí no ha sido sistemática ni en progreso. 


\section{Estrella Distante, comienza la historia}

Si bien Bolaño escribió Estrella Distante inmediatamente después del capítulo dedicado a Ramírez Hoffman en La Literatura Nazi en América, esta novela no se puede considerar una simple ampliación o desarrollo de ese capítulo. La fundamentación del tránsito del episodio a la novela es central en el gran relato bolañano. Con el expediente de delegar las decisiones en sus alter egos, Bolaño puede disfrazar su biografía, transgredirla e incluso traicionarla a veces, ganando una libertad infinita para desarrollar su trama con un itinerario. En esa fundamentación, que aparece en la introducción de Estrella Distante, Arturo Belano "invita" a Roberto Bolaño a escribir de nuevo la historia de Ramírez Hoffman, a recomenzarla desde otro lugar. Se encierran en su casa de Blanes durante un mes y medio y con el último capítulo en mano fabrican Estrella Distante.

En esta novela Bolaño marca rotundamente la separación de su yo de sus diversos alter egos. Los deja en libertad de acción, rechazando toda responsabilidad sobre los escritos que vendrán. Y entonces cambia los nombres de los personajes entre un libro y otro. Emilio Stevens pasa a llamarse Carlos Wieder (en alemán, significativamente, Carlos Otra Vez) y Ramírez Hoffman, Alberto Ruiz-Tagle. Las musas hermanas Venegas son ahora las hermanas Garmendia y el narrador protagonista es Arturo Belano en lugar de Roberto Bolaño, aunque el texto es igual en todo lo demás, al que aparece en "Ramírez Hoffman", lo deja extrañamente innominado:

"Era un Messerschmitt, dijo Norberto, y yo creo que venía del otro mundo. Le palmeé la espalda y le dije que seguramente era así."

Al final, en la peripecia con Abel Romero cambia el nombre Bolaño por la palabra amigo:

"Cuídese mi amigo, dijo finalmente y se marchó."

A partir de la introducción de Estrella Distante, el primer Bolaño se sumerge y se transforma de manera manifiesta y con toda comodidad en el autor invisible de B y a partir de entonces sus alter egos serán Arturo Belano, B, o Arturo B.

Pero B es mucho más que su alter ego; es su posibilidad de proyección en el tiempo y el espacio literarios. En conjunto, son una sola cosa y la versión ilimitada de sí mismos, sin restricciones. En esta coincidencia, la fábula y la confabulación están decididas y concertadas de 
antemano. De tal manera que hasta ahora tenemos dos partes en la construcción del personaje B: una, la pronta emergencia de la escenografía y de los personajes en Amberes. Otra, la transfiguración de Roberto Bolaño en Arturo Belano en Estrella Distante, a partir del capítulo "Ramírez Hoffman, el infame" de La Literatura Nazi en América.

Queda claro que ambas novelas comienzan a configurar buena parte del arquetipo de B. Sin embargo, estas historias, como tramas en el tiempo, no dan pie a un itinerario mayor. Sólo nos entregan una parte de la frase, si bien con casi todas sus asociaciones posibles. Son los primeros esbozos de los libros que conducirán al "Bibliotecario" archimboldiano. Sólo con la quinta novela, Los Detectives Salvajes, conseguiremos una visión más completa del devenir bolañesco en el tiempo. Y si agregamos a ella sus cuentos, como complemento, entonces la visión en progreso resultará nítida y podremos delinear una arquitectura espacio temporal con plenitud tanto en la historia como en el texto, lo que nos permitirá, a su vez, establecer no sólo un cosmos, sino un itinerario dentro de él.

\section{La definición de un itinerario y de una cosmografía}

B, autor/actor, aparece con potencia en Los Detectives Salvajes. Entrega en ella buena parte de las claves de su vida y la novela se transforma en un itinerario posible de su literatura y de su nomadismo. Al contrario de Amberes, que dispara magma originario hacia todos lados, Los Detectives Salvajes desarrolla un posible derrotero bolañesco en su máxima expresión y extensión, y lo hace dentro de un marco histórico, ordenando significados tanto hacia atrás (Amberes) como hacia delante (2666). En esta novela se vislumbra por primera vez un cronograma que permite dilucidar los caminos de B. Es posible rastrearlo en ella desde que llega a México en 1968 hasta su desaparición en África en 1996.

La novela está dividida en tres partes llamadas secuencialmente "Mexicanos perdidos en México" (1975); "Los detectives salvajes" (1976-1996) y "Los desiertos de Sonora" (1976). La primera y la tercera son un diario escrito por el poeta real visceralista Juan García Madero, que a la fecha sólo tiene 17 años. "Mexicanos perdidos en México" transcurre entre el 2 de noviembre y el 31 de diciembre de 1975, en México DF; "Los desiertos de Sonora" entre el 1 de enero y el 15 de 
febrero de 1976, en las carreteras y pueblos del norte de México y especialmente en los estados de Sonora y Chihuahua.

El relato de García Madero tiene una lógica positiva, encadenada, cronológica. Recorre el tiempo desde que conoce a los realistas viscerales hasta la partida con Belano, Ulises Lima, el inseparable amigo de B, y Lupe, la prostituta, hacia un destino incierto, atrapado por las circunstancias. En esta primera parte Arturo Belano y Ulises Lima son sólo referencias, salvo en la parte final, cuando deciden la búsqueda de Cesárea Tinajero, su musa poética.

En la tercera parte, García Madero narra diariamente la pesquisa in situ de Cesárea, su encuentro, el escape y el enfrentamiento con el despechado chulo Alberto que busca a Lupe, desencadenando el asesinato de Tinajero, la muerte de Alberto y el policía a manos de Belano y Lima, la huida de ambos en el coche de Alberto y su desaparición; y por último, la apropiación de Lupe y García Madero del legado de Cesárea: sus cuadernos y su casa. En ella la participación de Belano y Lima es directa. Son los protagonistas.

Entre esas dos secciones, que forman un continuo temporal, existe una contundente segunda parte que consiste en un coro polifónico bajtiniano de cincuenta y tres voces que intervienen en primera persona desde distintos momentos y lugares de América, Europa, África y el Medio Oriente, entrecruzándose, constituyendo el itinerario cronotópico de B y ampliando definitivamente sus fronteras de lectura.

Cada relato de la segunda parte de Los Detectives Salvajes da cuenta fragmentariamente de lo que sucedió entre 1968 y 1996 en la vida de $\mathrm{B}$, Ulises Lima y su grupo. Casi ninguna de ellas tendrá final. La incertidumbre permanente será una característica estructural de esta novela, lo que hace que se transforme en un puente entre una visión moderna del mundo - literatura oficial, progreso, migración, revolución, desarrollo, felicidad, relatos cerrados y grandes relatos- y otra posmoderna: el entusiasmo sin causas conocidas u objetivas, la multiplicidad de pequeños relatos fragmentados, la enfermedad, el mal o la derrota como destinos normalizados, el estar más que el ser, la historia abierta, etcétera.

Al no existir certezas, hay sólo simples historias sin fin, contadas por protagonistas o por actores que parecen secundarios aunque muchas veces no lo son, que intentan dar pistas, siempre dudosas, para que el lector cierre el relato, si quiere y si puede, sobre la historia del protagonista principal. Esto permite que la obra narrativa completa de Bolaño 
se entreteja y cada texto entre y salga de otro, que haya personajes que circulen por toda ella gestando la gran trama bolañesca como en un gran lienzo de Arcimboldo.

A través de las distintas voces de los treinta y dos cuentos que Bolaño planificó en vida para ser publicados, se completan los espacios y los tiempos de B. Recordemos que en diez cuentos participa directamente y son relatados por él mismo; en siete participa directamente, pero son relatados por otra persona; en otros tres, B relata historias que afirma que le han contado terceros a los que cede la palabra en un momento de la narración.

El viaje tras Cesárea Tinajero se convierte en una oportunidad para una reflexión completa sobre el estado del arte de la vida de Belano y Lima. En su periplo, confiesan un estado de malestar que no abandonará a $\mathrm{B}$ en todo su derrotero: han llegado tarde a la historia y a la literatura, cuando las revoluciones han fracasado o están anquilosadas, cuando la literatura latinoamericana ya tiene santos canonizados.

Es en el poema 'Sión' de Cesárea Tinajero donde podemos encontrar la clave del itinerario de B y la estructura global de todas sus peripecias.

\section{El poema de Tinajero y los caminos de $B$}

Cuando hallaron a Cesárea Tinajero en los lavaderos de un pueblo perdido del norte de México, en el desierto, el poeta realista visceral Juan García Madero hizo la primera descripción de ella. Le pareció una matrona capaz de acoger entre los pliegues de su humanidad a un ejército de poetas jóvenes y hambrientos.

Pero ¿es sólo eso lo que representa Cesárea Tinajero para B y su gran relato, una tinaja enorme donde guarecerse de las tempestades?

El poema 'Sión' ya se le había aparecido a Roberto Bolaño en Amberes, antes de ser Belano o B, como una secuencia fotográfica tomada en la playa de Castelldefels. Cuando, posteriormente, durante la conversación con el poeta estridentista Amadeo Salvatierra, en Los Detectives Salvajes, éste le mostró el poema de Tinajero, B lo interpretó de la misma manera que en Amberes: la línea recta: calma; la línea ondulada: tránsito hacia la desesperación; la línea quebrada: crispación y pesadilla. 

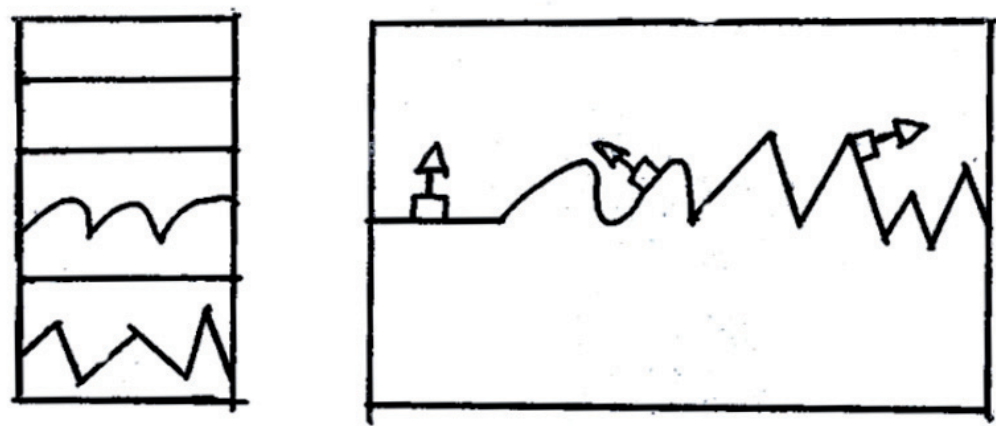

Fotos de la playa de Castelldefels, y otras (Amberes).

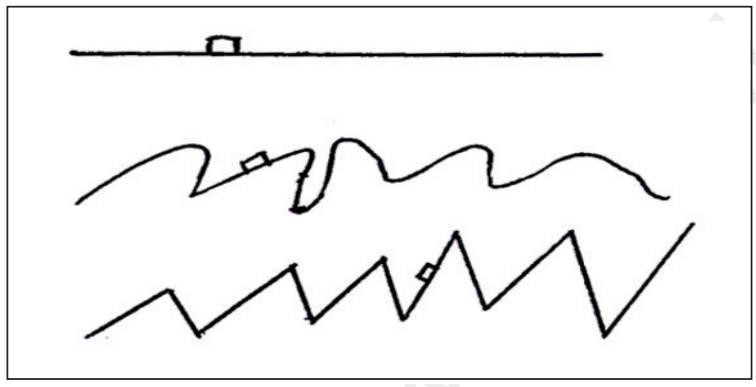

Poema 'Sión' (Los Detectives Salvajes).

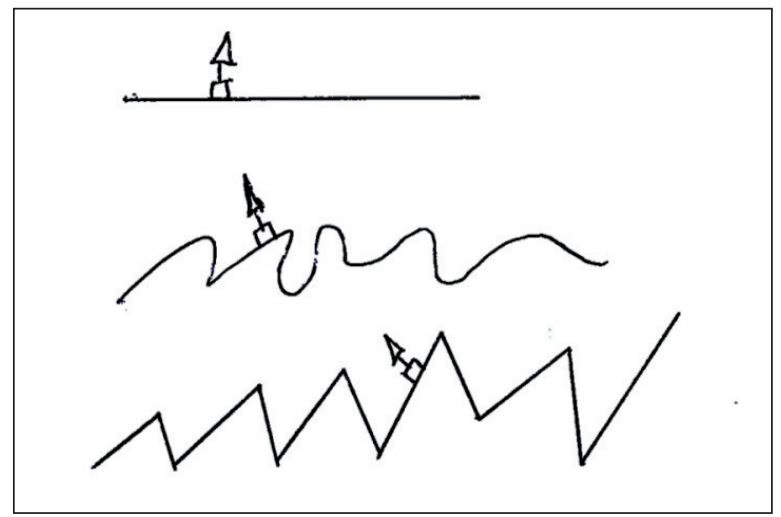

Elucubración de B sobre el poema ‘Sión' (Los Detectives Salvajes). 
B hizo que Salvatierra trazara una vela sobre un rectángulo que flotaba sobre las líneas, y afirmó que era el dibujo de un barco que navega desde la calma a la tormenta definitiva. Todos coincidieron en que esa afirmación sólo podía ser una broma, pero dejaron la posibilidad de que escondiera algo muy serio.

El poema es un adelanto en cámara rápida de todo lo que se avecina en la vida de B. Desde la calma hasta la borrasca sin término que culmina con su desaparición en África.

Tinajero, que no es sino su autoimagen femenina y, a la vez, su madre literaria, se convierte en una pitonisa de su destino; en su adelantada. Dibujó el mapa de su existencia futura, o, más bien, se transformó en el propio mapa de la trayectoria de B.

El transcurso de la vida de Belano, como el de Cesárea Tinajero, estaba previsto en el poema 'Sión' y el paso de las páginas demostrará que ocultaba nada menos que el itinerario de su gran relato, en una progresiva huida hacia la nada que B continuará en el cuadrado vacío, limitado por líneas intermitentes, que dibujó García Madero al terminar su diario en Los Detectives Salvajes, agregando un epitafio consecuente. El marco del dibujo desaparece, queda la hoja en blanco. La ruta hacia la nada queda anunciada en el papel.

¿Qué hay detrás de la ventana? (Los Detectives Salvajes).

B sacó así a Tinajero de su calidad de fantasma del desierto de Sonora. Al asesinarla literariamente, la expulsó para siempre del olvido, la llevó a la gloria y la convirtió en su propio destino. La depositó en un panteón para ir a sentarse a su lado en algún momento posterior. Le 
confirió antecedentes públicos e inmortales. Y él pasó a ser su discípulo oficial, acogido por la gran madre que lo predestinó a tener un lugar en su sistema político literario. Destino que culminaría en Barcelona en una carrera desaforada contra el tiempo por la necesidad de ser querido como escritor y hombre. Sólo le quedaba seguir su camino hasta las últimas consecuencias, antes de morir.

\section{La enfermedad, África y la huida hacia la ventana vacía (1994- )}

En junio de 1994, B confesó a su amigo Guillem Piña, que quería ir a morir a África. También le dijo lo mismo a su amante Susana Puig. Luego desapareció.

En 1996, Jacobo Urenda, un fotógrafo argentino-francés, encontró a B en Luanda, Angola. Urenda nos cuenta que le sorprendió la ambigüedad de B frente a la enfermedad en sus últimos días, también lo incoherente de sus actitudes ante la muerte. Nos hace ver que, por una parte, B aparentaba que la vida no le importaba nada y que, por otra, se cuidaba tomando sus medicinas con mucha puntualidad. Por ejemplo, Urenda afirma que cuando a B se le acababan los remedios, los buscaba con ansiedad, incluso encargándolos a Europa con algún viajero.

Tiempo más adelante, Urenda se volvió nuevamente a topar con él, ahora en Kigali, Ruanda, y cambió levemente su percepción de los deseos erótico tanáticos de $\mathrm{B}$. Ya no quería morir, pero tampoco quería volver a Cataluña. Estaba impresionado con la muerte de los demás, lo que relativizaba la proximidad de su propia muerte. Urenda se encontró por última vez con él en abril de 1996, en Liberia. Lo encontró en Brownsville, un pueblo cerca de Monrovia, la capital, en medio de un zafarrancho. Estaba junto a López Lobo, el famoso fotógrafo español de trincheras, a punto de partir a un lugar de difícil retorno. A partir de este momento del relato, B se evapora de cualquier estructura cronológica. En el cuento "Fotos", del libro Putas Asesinas, todavía lo encontramos en África. ¿Antes o después de verse con Jacobo Urenda? En ese cuento hojea La Poésie Contemporaine de Langue Française Depuis 1945, un volumen de poemas y fotografías de poetas francófonos. Está en el momento anterior a desaparecer para siempre. A través de "Fotos" conocemos su último pensamiento sobre la muerte: "la dictadura del tiempo es sólo un suspiro". 
De "Fotos" en adelante el nombre de B no volverá a emerger hasta la aparición de la nota que encontró Ignacio Echevarría, el editor de 2666, entre los papeles de Roberto Bolaño escritor, en los que afirma que fue Arturo Belano quien escribió esa novela. En ese momento se abre la ventana hacia la nada que dibujó García Madero. Una ventana capaz de desvanecerse y no dejar ningún vestigio una vez que $\mathrm{B}$ y los lectores la traspasen. Es el fin de la huida que le ha señalado Tinajero desde el poema 'Sión' y que él ha tomado como bandera de lucha. Por otra parte, es el comienzo de otra vida, oculta y anunciada, más tranquila, aunque quizás menos glamorosa ${ }^{3}$.

\section{El antihéroe perfecto, o cómo Arturo Belano siempre quiso ser Benno von Archimboldi}

La figura de B no se puede completar sin la otra mitad de él mismo: Benno von Archimboldi, aquel campesino alemán llamado Hans Reiter que en 2666 se convierte en un exitoso escritor ${ }^{4}$.

La primera vez que tenemos noticias de un Archimboldi en la narrativa de Roberto Bolaño es en Los Detectives Salvajes, cuando Luis Sebastián Rosado, a punto de ser seducido por el poeta bisexual Piel Divina, le dijo que no podía ir a su casa porque al otro día tenía que levantarse temprano. La causa del madrugón: iba a recibir al "novelista francés J.M.G. Arcimboldi”, que llegaba a Ciudad de México. Al ser preguntado por Piel Divina sobre quién era Arcimboldi, Rosado le respondió que uno de los mejores novelistas franceses, aunque su obra casi no estaba traducida al español, salvo alguna novela publicada en Argen-

${ }^{3}$ En el cuento "Las Jornadas del Caos" de su libro póstumo El Secreto del Mal, para el que se rescataron textos de su computador (escritos que quizás Bolaño nunca quiso publicar), aparece B cincuentón, preocupado por un viaje de su hijo Gerónimo a Berlín. Es la última vez que aparece B como personaje. La duda es si Bolaño, escritor real, quiso que ese texto alguna vez se conociera y no fue un borrador que el escritor prefirió no darle vida. En relación a esto mismo, acaba de aparecer una novela póstuma llamada El Tercer Reich. Es un borrador de 365 páginas corregida por un puntilloso editor de textos que deja sin alma a un Bolaño que parte de su carisma radica en la imperfección de sus escritos.

${ }^{4}$ ¿Son J.M.G. Arcimboldi y Benno von Archimboldi el mismo personaje? Parecieran ser dos escritores distintos, uno escribe en francés y el otro en alemán, tienen biografías distintas, pero resulta que, si investigamos, han escrito en parte los mismos libros. La creación en desarrollo de Arturo Belano hace al segundo hijo literario del primero, pero ¿no será otro disfraz de $\mathrm{B}$ para reconstruirse con datos biográficos múltiples y echar una cortina de humo sobre su identidad final? 
tina. Su segunda aparición también ocurre en Los Detectives Salvajes. Ahora en Israel, cuando Claudia, la enamorada de Ulises Lima, le esconde a Norman Bolzman, su novio entonces enfermo, el Tractactus de Wittgenstein y le pasa a cambio 'La Rosa Ilimitada', una de las novelas de J.M.G. Arcimboldi traducidas al español.

El origen del seudónimo Arcimboldi proviene, sin duda, del pintor milanés Giuseppe Arcimboldo, cuyas pinturas, como vimos, representan situaciones u objetos que como totalidad, vistos desde otro lugar, crean una nueva representación. Se especula que el nombre Benno sería un saludo de Hans Reiter, verdadero nombre de Archimboldi, a Benito Mussolini; otros piensan que es un saludo de Bolaño a Benito Juárez. Yo creo que el asunto es mucho más prosaico: uno de los autores principales que escribe sobre la obra pictórica de Arcimboldo se llama Benno Geiger. Autor que Bolaño tuvo que haber leído muchas veces. Es muy probable que haya tomado su nombre.

La historia principal de Archimboldi se desenvuelve en 2666. Fue escrita como un concierto de cinco tramas ligadas en un gran relato. Es la máxima expresión de B como autor/escritor.

Archimboldi se va construyendo, a lo largo de estas historias, en los escenarios de algunos de los males del siglo XX: las matanzas del nazismo y del comunismo, las guerras mundiales, la censura artística y el narcotráfico entre otros. En 2666, Bolaño intenta discutir sobre el papel del escritor en el nuevo siglo. Los temas se introducen a través del discurso de los personajes y también, y principalmente, por medio de una especie de novela dentro de la novela: los cuadernos del adolescente Boris Ansky, que Archimboldi hará suyos como una guía y el narrador se encargará de ir revelando gradualmente a los lectores.

Estoy de acuerdo con Christopher Domínguez, el crítico mexicano, cuando dice que 2666 es una novela bisagra entre el siglo XX y el XXI, ya que enlaza las historias más temibles del siglo pasado, que $\mathrm{B}$ integra en cada uno de sus textos, transcurran donde transcurran, con la incierta perspectiva de los comienzos del siglo XXI, que en 2666 se atisba infame y despiadado. B se plantea con estupor frente a la caída de los metarrelatos del siglo XX y con una indiferencia forzada frente a la asepsia histórica que pretende instaurar el comienzo del siglo siguiente. La condición de $\mathrm{B}$, de latinoamericano huido y de europeo en vías de consolidación, en camino hacia la muerte, lo convierten en un puente exquisito entre los dos momentos históricos. 
Benno von Archimboldi encarna a un escritor que se transforma en un testigo excepcional de una época que le resbala o no percibe del todo. Si bien Archimboldi, al igual que B, asume la escritura con un carácter exclusivo y excluyente, no ejercita la inteligencia crítica como una manera de resistir al poder y al mal como lo habría hecho un intelectual de la época o el propio $\mathrm{B}$, sino que más bien se convierte en un ser imperturbable que no está dispuesto a negociar con un sistema que para él no existe.

En 2666, el procesamiento de la historia está sometido a una triple digestión. La inocua que realiza el propio Archimboldi; la segunda que hace $\mathrm{B}$, como autor/escritor, desde un lugar histórico más amplio en el que se involucra en cuerpo y alma, y una tercera que hace Bolaño escritor dando espacios para que B construya un antihéroe a su gusto.

Así, este triple procesamiento está dirigido por un autor/actor desdoblado como autor/escritor: B, que desarrolla un tercer personaje, Archimboldi, para autocriticarse dándose la oportunidad de crear un antihéroe que inicie y convoque otras maneras de vivir la vida y la literatura, distintas a como él las ha vivido. Entonces, si bien es cierto que en 2666 se desarrolla un cierto linaje de la maldad, lo principal que ocurre es el renacimiento del personaje $\mathrm{B}$, a través del antihéroe Archimboldi, dirigido por Bolaño escritor.

La construcción de Archimboldi como personaje se hace primero en el capítulo "La parte de los críticos", a través de la historia de sus comentaristas más fieles: Jean Claude Pelletier, Manuel Espinoza, Piero Morini y Liz Norton, que lo van a buscar a Santa Teresa (trasunto de Ciudad Juárez), en México, donde recurren al profesor chileno Óscar Amalfitano, traductor de Archimboldi al español, para intentar hallarlo.

Y luego en "La parte de Archimboldi", su biografía, narrada por Arturo Belano, como se desprende de lo confirmado por Ignacio Echevarría en la nota a la primera edición de 2666, a que ya hemos hecho referencia. Las otras tres secciones del libro llamadas "La parte de Amalfitano", "La parte de Fate" y "La parte de los crímenes", aunque indirectamente relacionadas, son inseparables del corpus constituyente de Archimboldi, ya que entregan pistas sobre su itinerario general y desarrollan ciertas escenografías en su máxima expresión como, por ejemplo, la ciudad maldita de Santa Teresa.

B crea a su personaje Archimboldi con características que le hubiera gustado que fueran suyas, pero que por avatares de su historia no 
alcanzó o no quiso esforzarse por alcanzar como, por ejemplo, ser un escritor de culto, ganar dinero por derechos de autor y darse el lujo de la invisibilidad. Me refiero, por supuesto, al personaje autor/escritor B y no al escritor real Roberto Bolaño.

Archimboldi, al revés de B, no percibe la literatura como un sistema político. Para él la literatura no es un Estado reglamentado, con jueces, policías y árbitros, que somete y determina al escritor. Por el contrario, se mantiene al margen de los dos supuestos guardianes del sistema, el Mercado Editorial y la Crítica y, al ignorarlos, de un modo u otro, les impone sus propias reglas y códigos. Así como la literatura en el universo simbólico de B es un sistema político, un cosmos que entrega reglas de motivación, acción y desempeño, que determina qué es bueno y qué es malo, que declara quién gana y quién pierde; para Archimboldi la literatura es sólo un campo de acción personal que le permite manejar las riendas de lo que hace y de lo que no hace en la vida cotidiana.

A través de esta convicción determinante, relacionada con su más íntimo deseo de escribir, Archimboldi mueve a sus editores a publicarlo más allá de cualquier consideración de los guardianes de la Crítica. Archimboldi, al no sentirse tocado, y a pesar de estar en medio del sistema, determina inversamente al Mercado Editorial, conquistando a críticos y lectores antes de escribir.

Archimboldi, a diferencia de B que sufre por casi todo, prácticamente no tiene emociones. Sólo parece afectarle, puntualmente, el dolor de la muerte de su mujer, Ingeborg, y la lectura de los cuadernos de Boris Ansky que lo condujeron a ser escritor. Nunca ha esperado "llamadas telefónicas" de nadie. Es un ser del Tao, lo que está, está; lo que no está no está.

Tampoco existe en su vida algo similar a la enfermedad belaniana como horizonte fatal. Su productividad sólo está relacionada con su necesidad de comer y su declarado placer por escribir. Su historia es un signo de su naturaleza. Sus características de no apariencia, no fama y de literatura por la literatura son la base de su hechura como personaje y de su derrotero. Todo lo contrario de B, a quien angustia el fracaso en lograr identidad y reconocimiento como escritor antes de morir. B debe superar su desaparición para ser. Archimboldi simplemente es, aunque esté desaparecido. 
Archimboldi no tiene paraíso. Tampoco infierno. Me atrevo a decir que ni siquiera purgatorio, como era el camping para B. Vive y deambula en el limbo. Un lugar que está en el borde, pero que no alcanza a estar ni más allá ni más acá del margen, donde nada influye y todo está lejano a cualquier juicio, punto de vista o ideología. Un lugar de donde nunca se sale pero en el que puede gozar toda la libertad del mundo.

Archimboldi se desempeña entonces en un cierto paradigma del mal pero con el horizonte del placer de la obra, en el que su desaparición es parte de ella, y en esto obviamente se parece a B. Sin embargo, al contrario de éste, no sólo no aparece sino que acelera su olvido al lograr su baja definitiva del canon al conseguir que los críticos finalmente lo olviden, al buscarlo y no poder encontrarlo. Archimboldi nunca podrá ser hallado, porque eso atenta contra los deseos inconscientes de Arturo Belano, su creador.

La percepción archimboldiana le suma placer y gratuidad a la literatura, y en este sentido complementa la percepción bolañesca. Gracias a que Archimboldi no necesita establecerse como un escritor reconocido frente a sí mismo ni a nadie, puede gozar el acto de escribir desligado de toda culpa o ansiedad. Sin embargo, si bien no se establece como un factor de resistencia al poder, dejando más bien que sus corrientes pasen a través suyo como por un pájaro que se ha parado sobre una línea de alto voltaje, esto no quiere decir que no ha tenido que navegar sobre corrientes bravas y tomar medidas para no dejarse aplastar.

Ha debido constituirse como un desaparecido permanente. No sólo es un nómada sino que además es un ser sin rostro. Cuando le llega el momento glorioso de entrar a la literatura como profesional se interesa en una identidad falsa. Siente la necesidad imperiosa de ser alguien completamente nuevo. Así como B evade el rigor del sistema instalado y su orden simbólico con el nomadismo impenitente y la escritura desaforada, Reiter/Archimboldi lo elude primero cambiándose de nombre y posteriormente desapareciendo incluso de los ritos que le corresponderían como escritor famoso. Su nueva identidad no es un alter ego que le consienta sobrepasar sus limitaciones biográficas, como se le permitió a B a partir de la famosa introducción a Estrella Distante; en este caso se trata de alguien que quiere y necesita ser completamente 
otro y, como parte de ese proceso, cambia su nombre y desaparece en otra vida.

A partir de su nueva identidad, Reiter-Archimboldi gesta su obra de una manera absolutamente independiente y conduce sus estrategias de poder, deseo y resistencia exclusivamente en función de su adicción a escribir. De allí, como ya dije, que el Mercado Editorial y la Crítica no signifiquen ninguna amenaza para él.

Archimboldi sobrevivió a la derrota generacional de una manera distinta que B. Debió superar a la generación de la guerra y los conflictos sociales, pero no lo hizo ideológicamente sino escribiendo y sólo escribiendo. Solamente necesitó sus relatos. No se embarcó en ninguna epopeya personal. Miró desde su limbo particular las secuelas de ese mal en las sociedades contemporáneas, sin otro ánimo que el de no querer ser parte de ellas ni siquiera como un marginal. Ésa fue su venganza. Nunca se consideró un derrotado porque nunca luchó por nada específico. No le importó que desaparecieran los metarrelatos del siglo XX. Tampoco anunció su propia desaparición.

La historia de Archimboldi, desde el punto de vista de las relaciones de poder y deseo, entre los 8 y los 88 años, es la historia de un resistente pasivo, casi inconsciente. Al contrario que $\mathrm{B}$, su resistencia no se plasma en el legado que pueda dejar después de la muerte, sino en vencer la tentación de canonizarse o ser canonizado antes de su desaparición final. B construyó a Archimboldi como una muestra de lo que a él le hubiera gustado ser: un autor invisible, aunque respetado, que escribe lo que se le ocurre y vive de ello sin que la Crítica ni el Mercado Editorial lo molesten, que tiene una mujer que ama y que lo ama y una amante nada demandante; y que al final puede darse el lujo de desaparecer en su México inicial sin tener que darle cuentas a nadie.

Si hacemos el ejercicio de que no es otro que B quien está hablando por Archimboldi, al que usa como muñeco ventrílocuo, podemos concluir que un B tardío ha cambiado su visión de la literatura y se la ha inculcado a su personaje para resarcir su pasado. Por lo tanto el discurso archimboldiano vendría a reconstituir al personaje B. Y lo haría tanto a través de voces propias como de distintos personajes, aunque fundamentalmente por medio del escritor secreto Boris Ansky.

Arturo Belano corre contra el tiempo tras la gloria, se obliga a enfrentar el rechazo de un sistema que no le da entrada y a encarar una enfermedad que ha programado su final. Archimboldi no necesita 
correr. Sólo reconstruye a Belano encarnando un personaje que el sistema político literario no afectará. De ese modo, B se constituye primero por medio de una serie de actos de resistencia que el sistema literario termina por aceptar, dejándolo como un escritor central y, al mismo tiempo, marginal. Sin embargo, no contento con esto provoca su transformación archimboldiana para convertirse en un escritor que sólo vive para y por la literatura sin la necesidad de aparecer para ser.

De cerca vemos a B formado por distintos personajes, alter egos, héroes y secuaces, impulsado por una fuerza que quiere transformarlo en un escritor profesional dentro de un orden reglado por el Mercado Editorial y la Crítica. Benno von Archimboldi es empujado en sentido contrario por el mismo B con una gran fuerza que lo arroja a una galaxia donde existe la literatura pura, ajena a cualquier sistema político literario. B acepta esto, con el dolor que implica resucitar en otro, para producir por fin y sin ninguna restricción una polifonía abierta al infinito.

Veo ahora un nuevo "Bibliotecario" de Giuseppe Arcimboldo. Lo crea una constelación de personajes, historias y voces que prefiguran dos conocidas siluetas: las de Arturo Belano y Benno von Archimboldi. Si me alejo, comienzan a desaparecer y se sobrepone en ellas una nueva estampa que llena la sala del castillo de Skokloster. Un "Bibliotecario" que se parece infinitamente a Roberto Bolaño, el escritor de carne y hueso.

Recibido: mayo 2010. Aceptado: junio 2010. 